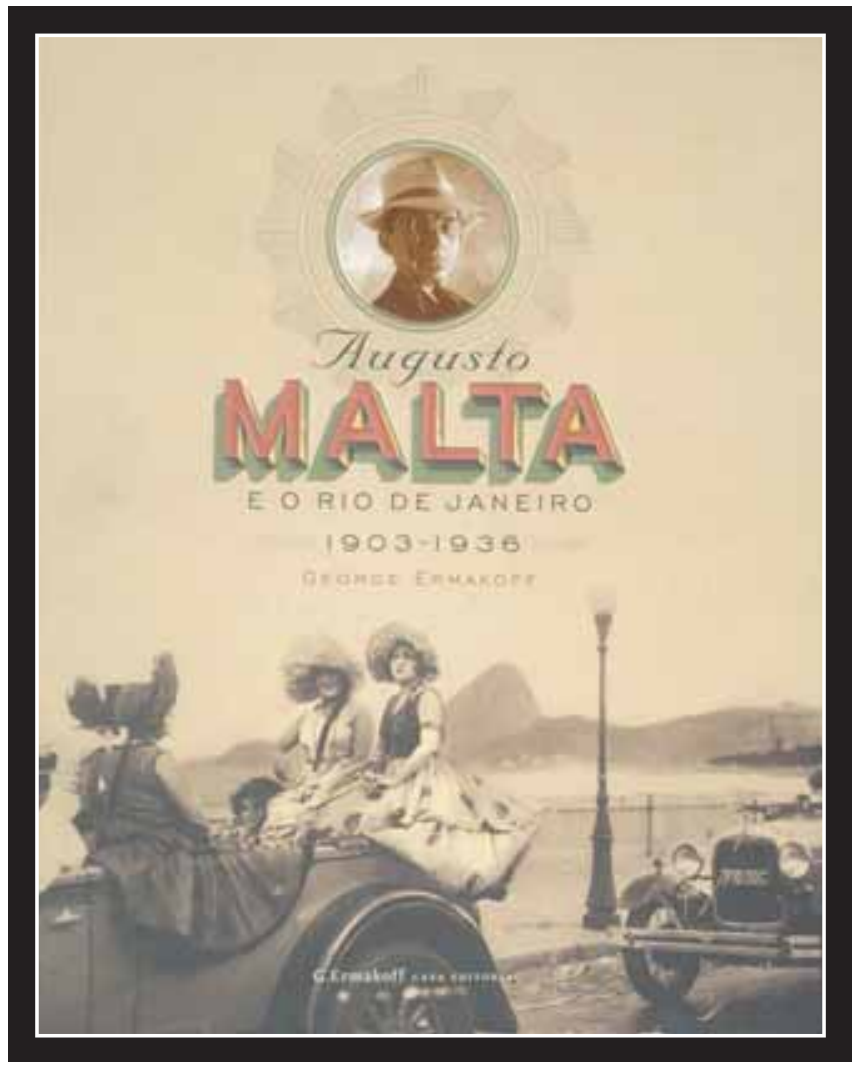

Augusto Malta e o Rio de Janeiro: 1903-1936, de George Ermakoff. 2. ed. Rio de Janeiro: G. Ermakoff, 2009. 288 p. 


\title{
Augusto Malta, o documentarista das transformações urbanas do Rio de Janeiro
}

\author{
Paulo César Boni *
}

Os registros fotográficos são documentos relevantes para a recuperação histórica e preservação da memória. Eles desfrutam desse status tanto para o levantamento e organização de sagas familiares quanto para a construção da história de instituições, empresas, ruas, avenidas, bairros, cidades, estados e países. Mais que a própria memória, os registros fotográficos são "gatilhos da memória”, ou seja, têm a capacidade de despertar lembranças intrínsecas e extrínsecas às imagens visíveis; eles convidam e instigam o leitor a extrapolar o simples recorte espaço-temporal congelado em algum tipo de suporte.

Ao olhar para uma fotografia, o leitor é capaz de recordar - e associar à imagem que tem à frente dos olhos - de "n" variáveis ou circunstâncias inerentes ao local, ao momento ou ao contexto do registro. O que está registrado detona o gatilho de sua memória e ele começa a se lembrar do entorno geográfico, das condições sociopolíticas, econômicas e culturais do momento do registro, de sons, cheiros, movimentos e emoções que não puderam ser registrados, mas que lhe vieram à mente assim que viu a fotografia.

No Brasil - e no mundo todo - a academia está consolidando a fotografia como documento histórico e utilizando-a como fonte de pesquisa. Por enquanto, a vertente mais intensa desse movimento está relacionada às fotografias de álbuns de família e de transformações urbanas de determinados lugares. Hoje, mais do que em qualquer outra época, as chamadas “fotografias antigas” de cidades são muito valorizadas, estudadas e pesquisadas. Todos os órgãos públicos (e também algumas iniciativas

\footnotetext{
* Doutor em Ciências da Comunicação pela Universidade de São Paulo (ECA/USP). Coordenador do Mestrado em Comunicação da Universidade Estadual de Londrina. Líder do Grupo de Pesquisa Comunicação e História, cadastrado no CNPq.
} 
privadas) que cuidam de acervos buscam recuperar, catalogar, digitalizar e disponibilizar fotografias que retratam as transformações urbanas de suas cidades, estados e do próprio país. O número de publicações de antigas coleções fotográficas - doadas a museus ou centros de preservação, ou mesmo de particulares - cresceu vertiginosamente nas duas últimas décadas, para deleite dos pesquisadores, satisfação dos que cultuam a memória e para o bem da sociedade.

Na última década - a primeira do século XXI e do III milênio foram publicados muitos livros sobre a história do Rio de Janeiro e a importância da fotografia para sua recuperação e preservação. Particularmente, como cidadão e pesquisador, fiquei muito feliz com a publicação da segunda edição de Augusto Malta e o Rio de Janeiro: 1903-1936, por George Ermakoff, com apresentação de Maria Inez Turazzi (G. Ermakoff Casa Editorial, 2009, 288 páginas). A publicação faz justiça à incomensurável obra fotográfica de Augusto Malta e destaca sua imprescindibilidade para a construção histórica da cidade maravilhosa.

Augusto Malta sempre foi visto, mas pouco lembrado. Ahistoriadora Maria Inez Turazzi diz na Apresentação do livro (página 10) que "há mais de um século o nome e as imagens do fotógrafo alagoano que escolheu o Rio de Janeiro para viver frequentam publicações oficiais, guias turísticos, revistas ilustradas e postais da cidade, sem contar o acervo de um bom número de instituições públicas e coleções particulares”, mas pouca gente na própria capital carioca, e menos ainda no resto do país, sabia relacionar a obra ao autor. É preciso ser justo: Augusto Malta não é pouco lembrado no meio acadêmico. Muitos já se debruçaram sobre sua vida e obra, o que rendeu alguns trabalhos de conclusão de curso, na graduação, monografias, em cursos de especialização, e dissertações de mestrado e teses de doutorado, na pós-graduação.

Mas, para o grande público, Augusto Malta era - e é ainda - muito menos conhecido que Marc Ferrez, lembrado, com justiça e mérito, ressalte-se, como o grande fotógrafo das transformações cariocas do final do século XIX e início do século XX. Na balança do reconhecimento 
histórico e popularidade, pesa a favor de Marc Ferrez o fato de seu neto, o colecionador e historiador Gilberto Ferrez, haver trabalhado exaustivamente a memória do avô. Neste sentido, Augusto Malta não teve a mesma sorte. Poucos de seus descendentes trabalharam para a preservação de sua obra e recuperação de sua memória. Ainda há vácuos em sua biografia. Ele viveu dois casamentos e teve filhos com as duas esposas. Seus netos do primeiro casamento pouco sabem de seus primos do segundo casamento, e a recíproca é verdadeira.

Portanto, neste momento, a obra de George Ermakoff vem recuperar, reconhecer e democratizar o acervo fotográfico de Augusto Malta. Fato raro no Brasil, com exceção de alguns best sellers da ficção, de autores estrangeiros - como as sagas de Harry Potter e de O Senhor dos Anéis -, o livro teve uma segunda edição imediatamente após a primeira, impressa em maio de 2009. A segunda foi impressa em outubro do mesmo ano porque, segundo o autor, "surpreendentemente, os 4.000 exemplares da primeira edição sequer esquentaram prateleiras; foram vendidos numa rapidez impressionante”. Ótimo saber que a sociedade carioca e leitores do Brasil afora ansiavam por alguma publicação que trouxesse, de forma valorizada e bem acabada, a vida e obra de Augusto Malta.

Filho de Claudino Dias de Campos e de Blandina Vieira de Malta Campos, carinhosamente chamada de Dona Iaiá, Augusto César de Malta Campos nasceu em Mata Grande, no estado de Alagoas, em 14 de maio de 1864. A família queria que ele fosse religioso, mandando-o inclusive morar e estudar com um padre, o que o deixou ressabiado. Quando tinha 22 anos, o padre que o acolhia faleceu e ele, mais do que depressa, aproveitou a oportunidade para mudar de cidade e de vida: foi para Recife e se alistou no exército. Foi o melhor para ele e para a Igreja católica, pois ele nunca teve a menor vocação para a vida religiosa. Mais tarde, chegou inclusive a se declarar ateu, apesar fotografar quase todas as igrejas católicas do Rio de Janeiro. Na carreira militar, sua opção de juventude, também não se deu bem: terminado o prazo de alistamento, foi dispensado. 
O próprio Malta relatou seu próximo passo1: "Imbuído de idéias republicanas, vim para a Corte, ingressando no comércio como auxiliar de escrita." Sua transferência do Recife para o Rio de Janeiro se deu no final de 1888, com a escravidão recém-abolida e em plena efervescência do movimento republicano. Segundo Malta, no mesmo depoimento, “a abolição foi ruinosa para a lavoura e para os próprios escravos”. Pouco tempo depois, foi promovido a guarda-livros na mesma empresa em que fora contratado como auxiliar de escrita, a Leandro Martins \& Cia., loja de móveis, tapetes e decorações de interiores. Dessa empresa, que ficava no centro do Rio de Janeiro (Rua do Ouvidor, 93/95), ausentou-se sorrateiramente na manhã de 15 de novembro de 1889 para acompanhar a Proclamação da República, no Campo de Santana. "Qual não foi o meu desapontamento ao ver surgir na praça interna Floriano Peixoto a cavalo", relatou decepcionado. Afinal, ele era alagoano como o "marechal de ferro" e conhecia bem sua fama. "Lá se foi a República”, diz ter pensado "com meus botões”. Nesse momento, infelizmente, Malta ainda não era fotógrafo.

Ainda antes de se tornar fotógrafo, se casou com a alagoana Laura Oliveira, com quem teve quatro filhas (Luthgardes, Arethusa, Callisthene e Aristocléa) e um filho caçula, Aristógiton. Dar nomes gregos aos filhos era uma de suas manias. Todas as filhas morreram de tuberculose, ainda jovens e solteiras. Malta sofreu todas essas perdas calado. Nunca escreveu sobre a morte das filhas; nunca comentou nada em entrevistas que deu a jornais e revistas.

Malta só se iniciou na fotografia em 1900, por acaso. Antes disso, tentou a sorte como comerciante e se deu mal. Montou uma casa de secos e molhados e faliu. Montou outra; faliu também. Começou a comercializar tecidos e inovou nesse ofício. Nessa época, todos os mascates visitavam seus clientes a cavalo; ele ia de bicicleta. George Ermakoff, no Álbum Biográfico da obra de Augusto Malta escreveu (página 18) sobre

\footnotetext{
${ }^{1}$ Esta informação consta de um recorte de jornal com uma entrevista de Augusto Malta. Como o texto foi recortado sem o nome do veículo e a data da publicação, não foi possível identificá-lo. Esta e outras entrevistas a jornais e revistas fazem parte de um arquivo montado pelo próprio fotógrafo e vendido por seus descendentes ao Museu da Imagem e do Som do Rio de Janeiro, depois de sua morte, onde foi nomeado como Álbum 37.
} 
o acaso que o iniciou na fotografia: "Em 1900, um de seus clientes, um guarda-marinha, possuidor de uma máquina fotográfica, propôs uma troca pela qual receberia a bicicleta de Malta. Este se encantou pelo aparelho e a proposta de troca foi aceita. Continuou a vender seus tecidos a pé e passou a utilizar o aparelho recebido para fazer retratos e belas vistas da cidade, ainda que amadoristicamente. Seu destino profissional estava começando a ser traçado.”

Só “acaso” é pouco para alguém se tornar um grande fotógrafo. Também é preciso competência e sorte. Competência Malta adquiria a cada imagem tomada. Era autodidata, curioso, um eterno insatisfeito que sempre procurava melhores resultados em suas imagens. Sorte? Bem, no início do século XX, sob a batuta do prefeito Francisco Pereira Passos, o Rio de Janeiro passava por grandes transformações urbanas (capitaneadas pelo engenheiro Paulo de Frontin) e de saneamento (comandadas pelo médico sanitarista Oswaldo Cruz) e essas obras precisavam ser fotografadas. Esta pode ser considerada a sorte de um contexto histórico. Além disso, Malta contou com a sorte de ter um amigo empreiteiro, Antônio Alves da Silva, admirador de suas imagens, que o apresentou ao prefeito Pereira Passos. Malta provavelmente tenha sido o primeiro profissional a ser contratado como fotógrafo para prestar serviços à administração pública. A contratação foi efetivada pelo Decreto Municipal 445, de junho de 1903, que o nomeou para o cargo de fotógrafo da Prefeitura do Distrito Federal, com salário mensal de 3.600\$000, um dos menores da hierarquia administrativa.

Num primeiro momento, ficou encarregado de fotografar os imóveis que seriam desapropriados para a construção da Avenida Central, hoje Rio Branco. O ritmo das obras era acelerado. Batizada pelos críticos de política do "bota abaixo”, a prefeitura tinha pressa nas desapropriações e as fotografias serviriam, então, para auxiliar nas indenizações pósdemolição. Boa parte dos proprietários era contra a demolição e queriam distância do “pessoal da prefeitura”. Por isso, a atividade de Malta era arriscada, pois poderia ser agredido por algum proprietário descontente. Em alguns casos, para driblar essa adversidade, usou a criatividade. 
Normalmente, convidava um punhado de crianças ávidas para posar para uma fotografia e as punha em frente ao imóvel que precisava ser fotografado. Para todos os efeitos, estava fotografando as crianças...

Depois das desapropriações, registrou o verdadeiro canteiro de obras em que o Rio de Janeiro se transformou. Como não tinha contrato “exclusivo" com a prefeitura, dedicou-se a fotografar a cidade, seu cotidiano e personagens (famosos e anônimos) por conta própria. Prestou serviços para pequenas e grandes empresas, entre as quais a Light e a Sul América, ainda hoje em atividade. Na página 31 do livro, no capítulo intitulado Álbum Biográfico, Ermakoff faz um inventário do resultado de suas pesquisas sobre a obra de Augusto Malta: "Sua produção fotográfica foi a mais variada possível. Fotografou dezenas de temas como os imóveis a serem desapropriados, demolições e a construção da Avenida Central, obras em logradouros da cidade, exposição comemorativa dos cem anos da abertura dos portos em 1908, quiosques, carnaval, vistas diversas da cidade para seus cartões-postais, personalidades políticas e culturais, exposição comemorativa do Centenário da Independência do Brasil em 1922, demolição do Morro do Castelo, cenas de praia, ressacas, enchentes, revoltas, repartições públicas, zonas de prostituição, grupos de crianças e de adultos, igrejas, teatros, escolas, comércio, casamentos e batizados, bondes, músicos, boêmia, cemitérios, eventos oficiais e particulares, além de acontecimentos políticos, favelas, cortiços, prados, esportes e até touradas, em pleno Rio de Janeiro.”

Em 1906, aos 42 anos, Malta ficou viúvo. Pouco tempo depois, passou a viver maritalmente com a babá de seus filhos, Celina Augusta Verschueren, que tinha metade da sua idade. Com ela, teve quatro filhos: Dirce, Eglé, Uriel e Amaltéa. Para quem havia perdido as quatro filhas do primeiro casamento para a tuberculose, Malta via com bons olhos as transformações urbanas e sanitaristas do Rio de Janeiro e desenvolveu profunda admiração pelo prefeito Pereira Passos, de quem veio a ser compadre, pois este batizou sua filha Aristocléa.

Malta também produziu cartões postais. Descobriu esse nicho mercadológico e se dedicou a ele com entusiasmo, no início. Muitas de 
suas “vistas” da cidade maravilhosa ganharam o Brasil e o mundo. Com o passar dos anos, a paixão pelos postais continuou, mas a produção arrefeceu. Tinha o saudável hábito de assinar e identificar a maioria de suas fotografias com anotações sobrepostas à imagem, normalmente nos cantos inferiores, principalmente as dos álbuns de família, para identificar o local, as pessoas e a data da tomada. Chegou, inclusive, a fotografar seus filhos Aristocléa e Aristógiton velando a irmã, Arethusa, vítima de tuberculose, em 31 de março de 1913. A identificação da “fallecida”, a data e o local do velório estão grafados no canto inferior esquerdo da fotografia. Essas anotações são consideradas um tesouro para os historiadores, pois ajudam - e muito - a recuperar a memória e dirimir dúvidas históricas.

Aos 72 anos de idade, mais de 30 deles dedicados à fotografia, Augusto Malta se aposentou em 25 de agosto de 1936. Foi substituído, no cargo de fotógrafo na Prefeitura do Rio de Janeiro, por seu filho Aristógiton. Apesar de haver convivido com figuras ilustres de seu tempo, com as quais tinha trânsito fácil e das quais conquistou respeito, o fotógrafo estava financeiramente no vermelho. A família numerosa e as adversidades, especialmente com a saúde de entes queridos, haviam-no feito gastar além do que tinha ou podia. Malta devia para fornecedores de produtos fotográficos. Adepto forçado da política do “devo, não nego, pago quando puder”, negociou dívidas em prestações mensais a perder de vista, mas honrou todas as parcelas.

Apesar de uma vez haver proferido ao amigo Noronha Santos a frase: “e eu quero lá saber do passado?”, quando este o convidou a ouvir antigas marchinhas para se lembrar dos carnavais passados, Augusto Malta sabia da importância histórica de seu acervo para a preservação da memória e cuidou de vender parte dele a instituições oficiais. Em 12 de maio de 1941, vendeu diversos álbuns fotográficos para a Biblioteca Nacional, sediada no Rio de Janeiro. Também vendeu imagens para o Museu Paulista, em 1942. Para manter seu padrão de vida, posto que os proventos da aposentadoria (como hoje, aliás) não eram suficientes, vendia fotografias para amigos saudosos de tempos e paisagens passadas. Dentre eles, dois 
compradores fiéis: o colunista Arthur Faveret e o historiador Charles Dunlop. Augusto Malta faleceu em 30 de junho de 1957, aos 93 anos, de insuficiência cardíaca, "não deixando nenhuma dívida”, como afirma Ermakoff na página 41 do livro sobre o fotógrafo.

O livro de George Ermakoff sobre Augusto Malta é uma deliciosa leitura, imprescindível não só para os amantes da cultura, estudiosos de história e apreciadores da fotografia, mas para todos os cidadãos conscientes e desejosos de conhecer mais sobre seu país, especialmente o Rio de Janeiro, antiga capital da República, que passou por um dos mais significativos processos de urbanização do mundo e foi todo registrado e documentado por um dos mais importantes fotógrafos documentaristas do século XX.

Para escrevê-lo, Ermakoff pesquisou a bibliografia disponível sobre Augusto Malta, entrevistou seus descendentes e garimpou fotografias em instituições oficiais e coleções particulares. Também reuniu documentos do biografado, inclusive notas fiscais de compra de produtos fotográficos, estampadas nas primeiras e últimas páginas do livro. É uma delícia ver e rever reproduções de notas fiscais de casas famosas como Marc Ferrez \& Filhos, Casa Niépce, Bastos Dias, Casa Bertea, Centro Photographico, de M. J. Pereira \& Comp. e outros. Ao todo, o livro traz 300 imagens, uma mais preciosa que a outra, que mostram do cotidiano carioca a eventos ímpares, como a Revolta da Chibata, em 1910; das obras das transformações urbanas aos monumentos da cidade maravilhosa; de anônimos a famosos; de trabalhadores braçais a transeuntes a passeio pelas principais avenidas e praças da cidade; da malandragem típica de alguns homens à beleza da mulher carioca; do flaner da minoria à correria da maioria. Ou seja, um retrato fiel do Rio de Janeiro das primeiras décadas do século XX.

Ancorado por seus estudos, Ermakoff afirma à página 26: “Augusto Malta foi um trabalhador incansável. Durante os 33 anos de atividades na Prefeitura produziu um vasto acervo iconográfico da cidade entre os anos de 1903 e 1936. [... Estima-se que tenha produzido algo entre 30.000 e 60.000 chapas." Para se ter uma ideia do quanto isso representa, basta 
dizer que ele produziu entre cinco e dez imagens por dia de trabalho. Para quem achar pouco, dada às tecnologias e facilidades atuais, é importante lembrar que, naquela época, Malta tinha que deslocar-se de bonde, de bicicleta ou a pé, carregando uma enorme e pesada câmera fotográfica, um tripé de madeira, um flash de magnésio e, claro, uma maleta com as “chapas” (negativos) de vidro.

Sorte? Acaso? Destino? Na Apresentação (página 11), Maria Inez Turazzi deixa claro a magnitude e a importância da obra, bem como traços da personalidade e do profissionalismo de Augusto Malta: “As belezas naturais, as transformações urbanas, os contrastes sociais, as celebrações públicas, os modismos importados e as mazelas do cotidiano carioca exaustivamente registrados por Malta marcaram de forma indelével o olhar, a carreira e a vida pessoal do fotógrafo.”

Sorte mesmo é a da memória nacional, em ter disponível para pesquisa um acervo tão precioso de uma época tão rica em transformações. Augusto Malta foi, sem dúvida, um dos maiores documentaristas da história da fotografia brasileira. E, por sorte, acaso, necessidade financeira ou consciência da importância de suas fotografias para a preservação da memória do Rio de Janeiro, não importa exatamente o motivo, seu acervo está preservado, e em boas mãos. E agora, com Augusto Malta e o Rio de Janeiro: 1903-1936, mais democratizado, apesar dos R\$145,00 como preço de capa. 